\title{
The Irish Sea Customs Border
}

\author{
A N N A JERZEWSKA
}

\subsection{Introduction}

This chapter provides an overview of how the Irish Sea customs border established under the Protocol functions in practice and what impact this new border has on companies trading between Great Britain (GB) and Northern Ireland. ${ }^{1}$ Given the 'unique circumstances on the island of Ireland', ${ }^{2}$ the border dividing Ireland and the UK was always going to be unlike any other border. The Irish Sea border, established under the Protocol, is a result of an imperfect compromise - an attempt to consolidate a range of requirements which, to a large extent, were contradictory.

\subsection{Dilemmas}

The need to respect the 1998 Agreement meant that introduction of a hard border with infrastructure and border checks between Northern Ireland and Ireland was impossible. The border needed to be as invisible and frictionless as possible. While various proposals were being put forward, in 2019 the Alternative Arrangements Commission ${ }^{3}$ was charged by the UK government with exploring the moving of border formalities away from the border. Unsurprisingly, the proposed solutions proved to be insufficient. At the end of the day, borders introduce friction, formalities and infrastructure. This is required in order for them to be able to fulfil their function. And, in this case, the new customs border was going to be the EU's and the UK's external border.

1 This chapter relates primarily to customs, which is only one part of the border process. Other chapters $(6,18-22)$ consider the implications of the 'regulatory border'.

2 Protocol Preamble.

3 The Alternative Arrangements Commission was an independent commission established by Prosperity UK and chaired by Conservative MPs Nicky Morgan and Greg Hands. The Commission's final report provided a range of alternative border arrangements for Northern Ireland. The report and the website have since been removed. 
For the EU, one of the priority was protecting the EU's internal market, ensuring that the goods entering Ireland are subject to the same rules and procedures as goods entering via any other EU border and that meant controls. At the same time, from the UK's perspective, there was a requirement to ensure that Northern Ireland will remain an integral part of the UK's territory. One of the key points for the UK was the need to protect its internal market, and the integrity of its customs territory, by ensuring unfettered access from Northern Ireland to GB.

It was also clear that the 'hardness' of the new border would depend on the type of the future relationship between the UK and the EU. In the simplest terms, the harder the Brexit option, the harder the border would have to be. The Political Declaration published in October 2019 together with the Withdrawal Agreement (WA) confirmed what was becoming increasingly evident - that the UK would seek to sign a free trade agreement with the EU. It then became clear that, wherever the border was situated, certain formalities and processes would need to be put in place on that border. With all the above points in mind, it was going to be a highly bespoke border - there were no off-the-shelf solutions as borders like this simply do not exist.

\subsection{The Protocol's Approach}

On the surface, the Protocol managed to square the circle. It introduced a border between Northern Ireland and GB, going down the Irish Sea. As described in earlier chapters, Northern Ireland stayed in the UK's customs territory but continued applying the EU's customs legislation as well as the EU's Common External Tariff for goods entering Northern Ireland, unless they are for use and consumption there. It allowed Northern Ireland to remain an integral part of the UK's customs territory and provided unfettered access for goods from Northern Ireland to GB. It also protected the EU's internal market by introducing customs formalities for goods entering Northern Ireland. In brief, it introduced a hybrid solution that at first glance managed to square the circle.

However, that perception was possible only because the Protocol provided a high-level legal framework for the solutions and left out the practical aspects of implementation and technical details. Crucial decisions that were bound to be technically challenging and politically sensitive were delegated to the newly formed Joint Committee (JC) ${ }^{4}$ and

${ }^{4}$ See Chapter 4. 
postponed to a later point in time. Key aspects of customs arrangements were to be decided by the JC and, in certain areas, were also to be determined by the UK government. This had significant implications for the ability of UK and Northern Irish stakeholders to prepare for the upcoming changes: despite the fact that the text of the Protocol was published, many crucial points around the operation of the new border remained unknown until late 2020.

Practical implementation aside, the Protocol created an unprecedented outcome. As discussed in earlier chapters, it created a situation where different customs and regulatory principles were to govern two parts of, at least de jure, the same customs territory: Northern Ireland and GB. It created a situation where there is a de facto customs and regulatory border going through the territory of the UK's customs territory. What is in place is a most unusual, asymmetric and one-sided border: asymmetric as it does not work the same way for movements in both directions; and one-sided as the customs formalities are applied on only one side of the border.

\subsection{Movements from Northern Ireland to GB: Unfettered Access}

According to Protocol Article 6(1), 'nothing in this Protocol shall prevent the United Kingdom from ensuring unfettered market access for goods moving from Northern Ireland to other parts of the United Kingdom'. Goods from Northern Ireland are able to enter GB without any customs or border formalities. Only a small number of controlled goods is subject to formalities when entering GB from Northern Ireland. ${ }^{5}$

On the one hand, the unfettered access for goods from Northern Ireland was necessary if Northern Ireland was to stay part of the UK's customs territory. Protocol Article 6(4) states: 'Nothing in this Protocol shall affect the law of the United Kingdom regulating the placing on the market in other parts of the United Kingdom of goods from Northern Ireland that comply with or benefit from technical regulations, assessments, registrations, certificates, approvals or authorizations governed by provisions of Union law referred to in Annex 2 to this Protocol.'

${ }^{5}$ Export declarations may be required for movement of goods from Northern Ireland into GB based on international obligations. One example would be goods covered by the Convention on International Trade in Endangered Species of Wild Fauna and Flora (CITES). Goods held under a customs special procedure in Northern Ireland would also require an export declaration. 
On the other hand, goods to be placed on the market in Northern Ireland need to comply with EU regulation, while goods produced in the rest of the UK do not. If, at some point, the two sets of rules were to diverge substantially, this could pose a problem. Goods produced in Northern Ireland according to the EU's regulations would still have unfettered access to the UK market. Would the same be the case for goods produced under the same rules in other parts of the EU? It would be difficult for the UK to argue that goods produced in the EU would need to meet UK rules to enter the UK's market, while Northern Ireland goods would not have to meet these conditions. At the same time, Northern Ireland products can benefit from UK trade agreements with other third countries while (at least in principle) they are not eligible for preferential treatment under the EU deals.

Unfettered access to GB raises further questions. For example, what constitutes a Northern Ireland product and, more importantly, how can we verify it as such? Article 6(2) states that the Protocol aims to facilitate trade between Northern Ireland and GB in accordance with applicable legislation and taking into account their respective regulatory regimes as well as the implementation thereof. The JC is responsible for reviewing this part and ensuring that controls at the ports and airports of Northern Ireland are kept to a minimum.

According to the government's guidance, unfettered access is granted to qualifying Northern Ireland goods. ${ }^{6}$ Goods arriving in Northern Ireland from the rest of the EU do not qualify for unfettered access if they are moved through Northern Ireland into Great Britain for an avoidance purpose'. However, there is no mechanism to verify or enforce these rules. The guidance mentions that a long-term regime qualifying which businesses can be considered established in Northern Ireland will be determined in 2021. In June 2021, this was still to be published in due course'.

In practice, with a lack of formalities and controls for goods entering GB from Northern Ireland, the issue of trans-shipment from the EU is a considerable risk, especially in cases where there is an incentive resulting from a difference in applied trade policy measures such as customs duties or anti-dumping duties. It is likely that, in addition to the new long-term qualifying regime, some form of control of which

${ }^{6}$ For guidance on moving qualifying goods from Northern Ireland to the rest of the UK, see www.gov.uk/guidance/moving-qualifying-goods-from-northern-ireland-to-the-rest-ofthe-uk. 
goods have unfettered access to GB from Northern Ireland will need to be introduced.

\subsection{Movements from GB to Northern Ireland: Tariffs or No Tariffs?}

Given that the EU's customs legislation, the Union Customs Code (UCC), applies to Northern Ireland, goods entering Northern Ireland are, as a result, subject to certain customs and border formalities. ${ }^{7}$ However, the formalities have only been introduced on the side of the border that is governed by the UCC. Normally, when a good is traded internationally, there are export formalities and import formalities. An export declaration needs to be submitted to export a product from one territory and an import declaration to import it into another.

This is not the case when it comes to the Irish Sea border. Goods are not 'exported' from GB. After all, at least on paper, it is the same customs territory. They are, however, 'imported' into Northern Ireland as required by the UCC. What this means in practice is that traders importing into Northern Ireland are required to submit customs paperwork and comply with border procedures. This includes a pre-notification and a customs declaration together with any other documents and formalities that may be necessary for their particular product (eg, health certificates for goods subject to SPS controls). GB traders exporting goods to Northern Ireland are not required to submit an export declaration or to complete other formalities.

This creates a new administrative burden for Northern Ireland traders which will be explored further in the later part of this chapter. But what about tariffs? If the goods enter Northern Ireland, formally a part of the UK's customs territory, are they subject to the EU's Common External Tariff? Protocol Article 5(2) states: 'No customs duties shall be payable for a good brought into Northern Ireland from another part of the United Kingdom by direct transport, notwithstanding paragraph 3, unless that good is at risk of subsequently being moved into the Union, whether by itself or forming part of another good following processing.' In this, slightly confusing, way, the idea of goods 'at risk' has been introduced. Goods entering Northern Ireland are not subject to customs duties unless

7 'The UK's Approach to the Northern Ireland Protocol' Command Paper, published 20 May 2020, outlines the UK government's position on the implementation of the Protocol including which checks and formalities are applied on the Irish Sea border. 
they are considered at risk of entering the EU market via Northern Ireland and Ireland. Protocol Article 5(2) makes it clear that goods will be considered at risk unless:

(i) they are not subject to further commercial processing in Northern Ireland (which indicates that goods subject to commercial processing would automatically be considered at risk), or

(ii) they fulfil criteria that were to be determined by the Joint Committee.

Determining the criteria for goods at risk was one of the crucial decisions that were delegated to the JC. It was also one of the elements of the Protocol that was likely to significantly impact Northern Ireland's traders. This was perhaps the most technically difficult and at the same time the most crucial part of the implementation of the Protocol. It required the final destination of the product to be determined and declared at the time of import into Northern Ireland, which is far from the usual practice. Normally, it is the origin of the product, where it was made and processed, that is declared to customs. With the exception of certain special customs procedures that suspend customs duties, the destination of the product, once it has been imported, is of little relevance to customs authorities.

Another issue is that the final destination of products cannot be verified at the time of import. What guarantee do the customs authorities have that the product will end up in the market declared at the time of importation of the goods into Northern Ireland? What if the Northern Ireland importer was to sell the product to another local company who then decided to sell it to a company in Ireland? Can Northern Ireland importers guarantee that their products are not at risk of entering Ireland and thus the EU market?

Working out how to determine goods 'at risk' required an innovative approach. As described in the author's UK Trade Policy Observatory (UKTPO) blog, there was a delicate balance to be struck between actually being able to track the goods entering the EU market and limiting the amount of additional administrative burden for businesses. ${ }^{8}$ The author proposed three ways of determining the final destination of the products at the time of import with a varying degree of burden for the private sector:

(i) by tariff line, which would entail an in-depth analysis of existing trade flows, in order to assess which goods are likely to enter the EU

8 A Jerzewska, 'Determining Goods at Risk' UKTPO (UK Trade Policy Observatory) (14 January 2020) https://blogs.sussex.ac.uk/uktpo/2020/01/14/determining-goods-atrisk/. 
market, although, in the absence of available trade data on tariff line level, such analysis would be difficult to conduct;

(ii) by product or shipment, which would entail the importer having to submit a declaration regarding the final destination, at the time of import, similar to the current origin statement, and would require appropriate controls to be introduced to reduce any incentives to transgress; or

(iii) by company, which would require authorized companies to provide documentary evidence post-importation to demonstrate where the goods ended up, although, while feasible in principle, this would be more difficult for smaller companies because of the additional costs and complexities that it would involve.

The JC's decision did not embrace any of these options entirely; rather, it used a hybrid approach. The decision of the JC on determining goods at risk was published on 17 December 2020, less than two weeks before the Irish Sea border was brought into effect. ${ }^{9}$ Article 2 of the Decision specified that goods would not be considered subject to commercial processing, and as such considered at risk, if the importer had an annual turnover of less than $£ 500,000$ or if the processing in Northern Ireland was for the purpose of:

(i) the sale of food to an end-consumer in the UK;

(ii) construction, where the processed goods form a permanent part of a structure that is constructed and located in Northern Ireland by the importer;

(iii) direct provision to the recipient of health or care services by the importer in Northern Ireland;

(iv) not-for-profit activities in Northern Ireland, where there is no subsequent sale of the processed good by the importer; or

(v) the final use of animal feed on premises located in Northern Ireland by the importer.

Article 3 further clarified that the goods would also not be considered at risk if the 'duty payable according to the Union Common Customs Tariff is equal to zero', or when the importer has been authorized to bring goods into

9 Decision No 4/2020 of the Joint Committee established by the Agreement on the withdrawal of the United Kingdom of Great Britain and Northern Ireland from the European Union and the European Atomic Energy Community of 17 December 2020 on the determination of goods not at risk [2020/2248], https:/ec.europa.eu/info/sites/default/ files/decision-4-determination-goods-not-risk_en.pdf. 
Northern Ireland for sale to or final use by end-consumers in Northern Ireland. Such authorizations would be granted by the UK government. ${ }^{10}$

Returning to the earlier question, how would a Northern Ireland importer know whether their goods were subject to tariffs? The Decision of the JC was subsequently supplemented by guidance from the UK government which attempted to simplify the above conditions. It explained that goods would not be subject to tariffs based either (i) on the applicable duties or (ii) on whether the trader was authorized. Goods would not be considered 'at risk' based on applicable duties when the applicable EU duty was zero (including under the Trade and Cooperation Agreement (TCA)) and, if the goods were going to be further processed, provided they met additional requirements listed in the guidance. ${ }^{11}$ On 15 December 2020, the UK government announced the UK Trader Scheme - a scheme for qualifying businesses to self-declare that their goods entering Northern Ireland were to remain in Northern Ireland. ${ }^{12}$

With only two weeks left before the Irish Sea border became operational, companies were given little time to understand what qualifying means and whether or not their products would meet the 'not at risk' criteria. Given the lack of sufficient time to even process the applications, companies were asked to self-certify and were given provisional authorizations until their applications could be reviewed. Companies were asked to ensure that they were eligible and had sufficient evidence to provide in the short amount of time available and without much support.

Finally, if goods do not meet any of these criteria and are still considered 'at risk', the Protocol provides one more option. Article 5(6) specifies that the UK may reimburse or waive the duties or 'compensate undertakings to offset the impact' (provided this is in accordance with the EU's state aid rules). Towards the end of December 2020, the UK government provided the first details of this wavier scheme. Companies may claim reimbursement or waiver of duties up to a maximum of $€ 200,000$ of aid over three tax years. ${ }^{13}$ In order to take advantage of this option, companies are required to declare it on a customs declaration at the time of import and to submit

${ }^{10}$ Art 5(1) of the Decision. Additional rules were put in place for goods entering Northern Ireland from outside the UK and the EU.

11 www.gov.uk/guidance/check-if-you-can-declare-goods-you-bring-into-northern-ire land-not-at-risk-of-moving-to-the-eu\#processing.

12 UK Trader Scheme launched to support businesses moving goods from Great Britain to Northern Ireland press release, December 2020, www.gov.uk/government/news/uktrader-scheme-launched-to-support-businesses-moving-goods-from-great-britain-tonorthern-ireland.

${ }^{13}$ In accordance with state aid rules. 
additional paperwork. At the time of writing, it is possible to apply for the waiver only at the time of import (with retrospective claims potentially being possible at a later date). It is also currently not possible to claim duties on goods entering Northern Ireland from countries outside the UK and the EU or when a business is involved in the production of agricultural products or fishery and aquaculture.

If all of the above sounds confusing, that is because it is. What did not help was the fact that the guidance provided to simplify the legal language of the Protocol and the JC's Decision was often written in a way that was difficult for traders to follow. For example: 'Goods which are subject to commercial processing, where the additional requirements to declare these goods "not at risk" are not met, cannot be declared "not at risk", and are therefore automatically "at risk". ${ }^{14}$ The reason behind this confusion, uncertainty and opacity seems clear: the decisions necessary to implement the Protocol were made at the very last minute. As a result, the interpretation and the guidance supporting these decisions were produced and published weeks, and sometimes only days, before the Irish Sea border was implemented. A particular piece of guidance relating to the Irish Sea border was published on 31 December $2020 .^{15}$

The guidance felt rushed and unclear. Traders were given less than two weeks to familiarize themselves and adapt to new rules over the December holiday period and with only a few working days left before the end of the year. Some of the schemes and guidance documents were not available until well into 2021. At the beginning of June 2021, some elements of the guidance were still awaited. ${ }^{16}$ All this demonstrates how last-minute the delivery of this border was. In addition, the new guidance regarding the Irish Sea border was made available at the same time as the text of the TCA between the EU and the UK was published. It was

14 www.gov.uk/guidance/check-if-you-can-declare-goods-you-bring-into-northern-ire land-not-at-risk-of-moving-to-the-eu.

${ }^{15}$ For guidance on sending parcels to and from Northern Ireland, see www.gov.uk/guid ance/sending-parcels-between-great-britain-and-northern-ireland.

${ }^{16}$ Another example could be the Trader Support Service (TSS). The TSS programme was introduced by the UK government to mitigate the lack of sufficient number of customs agents and to support the submission of import declarations into Northern Ireland. The tender for this system was conducted less than four months before the system was due to go live. As a result of a last-minute delivery of the system and the significant difficulties in hiring a number of customs experts to support the scheme at the last minute, traders have experienced a range of problems with the service since January 2021. In the author's experience of working with private sector companies, many have reported being given contradictory advice when contacting the TSS team on different days. 
difficult enough for experienced customs practitioners to keep on top of the newly published texts and guidance in the second half of December, let alone for smaller Northern Ireland companies with little or no experience in customs and international trade.

\subsection{Impact on Traders}

The challenges and the uncertainty faced by traders in Northern Ireland in the months around the end of the transition period were unparalleled. It was impossible for any company to be fully ready for January 2021 as rules and procedures were being worked out as days progressed, with every new import and every new issue.

But, apart from tariffs, why was adjusting to the new rules so challenging? Just how much of an inconvenience are the new customs border formalities? And, more importantly, were the difficulties and the additional burden only temporary or were these issues that traders in Northern Ireland would have to deal with well into the future?

While often referred to as 'just a form', customs and border formalities have significantly changed how companies trade. In the first instance, a pre-notification needs to be submitted when goods are imported into Northern Ireland. In response to increasing concerns regarding the threat of terrorism and the safety of international supply chains, many territories introduced a requirement for a safety and security prenotification. While these forms are submitted electronically and by carriers and other logistics providers, traders are asked to provide information required for the form in advance of importation.

Traders themselves are responsible for declaring imports to customs authorities. This is done by submitting a customs declaration. A customs declaration is a way for customs authorities to collect a range of information about the traded product and the companies involved in the process. This information is used for a number of purposes including calculating tariffs, determining whether goods can benefit from reduced tariffs under a trade deal, calculating import value added tax (VAT) and applying a range of other trade policy measures. It is also used for compliance monitoring purposes.

In the majority of cases, companies do not submit customs declarations themselves. A third-party provider, such as a customs broker, shipping agent or freight forwarder, submits the declaration and liaises with customs authorities on the company's behalf. Companies importing into Northern Ireland also have an option to use the free, governmentsponsored Trader Support Service (TSS). Yet, even then, it is the 
company that needs to provide customs data that is submitted via a customs declaration and, more importantly, it is the company that is legally liable for the correctness of this data.

Providing and collecting customs data is the most time-consuming part of the customs process for most companies. According to the United Nations Conference on Trade and Development (UNCTAD), an average cross-border transaction involves up to 30 different parties and around 40 documents with about 200 data elements, most of which need to be reentered into several systems. ${ }^{17}$ These figures cover other types of documentation necessary for trading goods internationally, not only customs, for example financial documentation that would enable the company to provide a financial guarantee for customs debt. However, a customs declaration itself has more than fifty data fields. Some of the data elements seem relatively straightforward, for example information about the importer or exporter. However, even such information has clear legal implications - who is liable for any debt? Furthermore, some data elements require an understanding of complex customs rules.

All products on the customs declaration need to be allocated a correct Harmonized System (HS) commodity code. ${ }^{18}$ Customs value needs to be established. This is done in accordance with strict international customs rules. Declaring goods under an incorrect commodity code or customs value might lead to an incorrect amount of duty and import VAT being collected. This might, in turn, lead to non-compliance, penalties and audits. The origin of goods needs to be determined. All this data needs to be collected, verified and entered into different systems.

A common belief is that each company has all the information necessary to complete a customs declaration easily available. This is not necessarily the case. Unless a company is importing or exporting, it would not have gone through the lengthy and difficult process of classifying its products. Furthermore, the information needed to classify, determine the value and origin of goods is often not held in the same place within the company. While this sounds simple to address, it often is not. Many companies, even larger and experienced importers and exporters, spend a considerable amount of time collecting, analysing, preparing and maintaining customs

17 For more information, see www.wto.org/english/thewto_e/minist_e/mc9_e/brief_trad fa_e.htm.

18 The Harmonized System (HS) Classification, also called the HS Nomenclature, is the World Customs Organization's Harmonized Commodity Description and Coding System. It is an international customs classification system which allocates a unique six-digit HS code to each group of products. Each imported product has to have a commodity code. 
data. While there are many customs IT solutions on the market, their uptake is not very widespread; in many companies, classification and origin calculations, for example, are still done manually.

Providing customs data to the authorities, or even to a customs broker, requires ongoing work. The team needs to monitor and update the data on a continuing, or at least periodic, basis. The UK's HM Revenue and Customs (HMRC) has assessed the amount of time required to prepare a customs declaration. ${ }^{19}$ For high-volume traders submitting their own declarations, HMRC's research suggests that one hour, forty-five minutes is needed per declaration. ${ }^{20}$ For high-volume traders using a customs broker to submit declarations, HMRC has estimated that one hour is necessary per declaration in order to prepare the needed information. This all requires additional resources, additional time and effort - and, as a result, ends up being an additional burden and cost for Northern Ireland companies that import goods from what is technically part of the same customs territory. If the Northern Ireland importer is not using the TSS service, there is also an additional cost: customs brokers charge fees for submitting import declarations on behalf of their customers.

\subsection{Conclusion}

The new Irish Sea border represents a profound shift in the way in which trade between GB and Northern Ireland is done. What, until January 2021, was an internal movement of goods subsequently became an actual import. The impact this will have on the volume and nature of trade between Northern Ireland and the rest of the UK, as well as on the existing supply chains, remains to be seen. In July 2021, the UK government proposed a radical renegotiation of the Protocol which, if accepted, would have resulted in many of the fundamental elements of the Protocol discussed in this chapter being changed. However, the UK's proposals in this respect were immediately rejected by the Commission. ${ }^{21}$

${ }^{19}$ HMRC, 'Impact Assessment for the Movement of Goods if the UK Leaves the EU without a Deal' (3rd edn, 2019) www.gov.uk/government/publications/hmrc-impact-assessment-forthe-movement-of-goods-if-the-uk-leaves-the-eu-without-a-deal/hmrc-impact-assessmentfor-the-movement-of-goods-if-the-uk-leaves-the-eu-without-a-deal-third-edition.

${ }^{20}$ Ibid.

${ }^{21}$ HM Government, Northern Ireland Protocol: The Way Forward (CP 502, July 2021). These proposals are discussed in more detail in 'Update: Developments from July 2021 to September 2021' at the front of this book. 